\title{
A MOTIVAÇÃO NO TRABALHO DA EQUIPE DE ENFERMAGEM ${ }^{1}$
}

Marta Cristiane Alves Pereira ${ }^{2}$

Neide Fávero ${ }^{3}$

Pereira MCA, Fávero N. A motivação no trabalho da equipe de enfermagem. Rev Latino-am Enfermagem 2001 julho; 9(4):7-12.

Estudo descritivo, realizado em um hospital universitário, com o propósito de apreender alguns aspectos que intervêm na motivação humana e suas implicações no resultado do trabalho. Utilizou-se como instrumento de coleta de dados a entrevista semi-estruturada e gravada, aplicada a 18 profissionais da equipe de enfermagem, sendo 6 enfermeiros e os demais auxiliares e técnicos de enfermagem. 0 material apreendido foi submetido à técnica de análise de conteúdo, permitindo identificar o "Trabalho em si" como categoria mais citada como motivadora e a "Organização do Trabalho" como maior desmotivadora, sendo que as sugestões mais citadas referem-se ao "Relacionamento Interpessoal" e a "Organização do Trabalho".

PALAVRAS CHAVE: motivação, equipe de enfermagem, trabalho

\section{MOTIVATION IN NURSING TEAM WORK}

This is a descriptive study conducted in a university hospital with the purpose to apprehend some aspects influencing human motivation and their implications to work results. A recorded semi-structured interview was used for data collection which was applied to 18 members of a nursing team, of whom 6 were nurses and 12 were nursing auxiliaries and technicians. The apprehended material was submitted to the content analysis technique, which enabled the identification of "Work Itself" as the most frequently cited category considered to be motivating and "Work Organization" as the most unmotivating. The most cited suggestions referred to "Work Organization" and to "Interpersonal Relationship".

KEY WORDS: motivation, nursing, team, work

\section{LA MOTIVACIÓN EN EL TRABAJO DEL EQUIPO DE ENFERMERÍA}

Estudio descriptivo, realizado en un hospital universitario, con el propósito de comprender algunos aspectos que intervienen en la motivación humana y sus implicaciones en el resultado del trabajo. Se utilizó como instrumento de recolección de datos la entrevista semiestructurada y grabada, aplicada a 18 profesionales del equipo de enfermería, siendo 6 enfermeros y los demás auxiliares y técnicos de enfermería. El material recolectado fue sometido a la técnica de análisis de contenido, permitiendo identificar el "Trabajo en si" como la categoría motivadora más citada y la "Organización del trabajo" como la más desmotivadora, siendo que las sugerencias más citadas se refieren a la "Organización del trabajo" y a las "Relaciones Interpersonales".

PALABRAS CLAVES: motivación, equipo de enfermería, trabajo

\footnotetext{
${ }^{1}$ Trabalho extraído da Dissertação de Mestrado "Aspectos motivacionais da equipe de enfermagem no trabalho" - Programa de Pós-Graduação em Enfermagem Fundamental - Escola de Enfermagem de Ribeirão Preto da Universidade de São Paulo; ${ }^{2}$ Enfermeira, Mestranda do Curso de Pós-Graduação, e-mail: alvespereiramc@bol.com.br; ${ }^{3}$ Professor Titular, e-mail: nfavero@eerp.usp.br, da Escola de Enfermagem de Ribeirão Preto da Universidade de São Paulo, Centro Colaborador da OMS para o desenvolvimento da pesquisa em enfermagem
} 
INTRODUÇÃO

$N_{\text {o cotidiano prático da enfermagem, caracterizado por }}$ atividades que exigem alta interdependência, a motivação surge como aspecto fundamental na busca de maior eficiência e, conseqüentemente, de maior qualidade na assistência de enfermagem prestada, aliada à satisfação dos trabalhadores.

A prática gerencial da enfermagem, enquanto busca de possibilidades no desenvolvimento de linhas sensíveis e racionais para lidar com as pessoas em situação de trabalho, leva-nos ao interesse pelo estudo do comportamento e dos motivos que levam as pessoas a agirem, pois alguns trabalham por dinheiro, outros por segurança e outros ainda por prazer ${ }^{(1)}$.

Acrescentando-se a isto, algumas pessoas que trabalham por dinheiro, em determinado momento, deixam de responder ao sistema de incentivo financeiro, assim como as pessoas que evidenciam fazer uso de suas aptidões e depois recusam funções que representam maior desafio e outras que, apesar de menos motivadas no trabalho, mantêm elevada a qualidade do que fazem ${ }^{(2)}$.

$\mathrm{Na}$ tentativa de nos aproximarmos à definição do termo motivação, retomamos sua origem na palavra motivu, do latim, que significa "que move ou o que pode fazer mover"(3). Entretanto, há autores que definem o termo "como uma inclinação para ação que tem origem em um motivo", e motivo seria uma necessidade que, atuando sobre o intelecto, faz a pessoa movimentar-se ou agir ${ }^{(4)}$.

Referindo-nos especificamente à motivação humana no trabalho, aproximamo-nos de conceitos que afirmam que as pessoas, ao serem indagadas sobre o que queriam do trabalho, quando informavam sentimentos de felicidade, freqüentemente descreviam fatores relacionados às suas tarefas ou eventos que indicavam êxito e possibilidade de crescimento profissional. Ao contrário, quando relatavam sentimentos de infelicidade, estes não eram associados ao próprio trabalho, mas às condições que 0 cercavam ${ }^{(5)}$.

Segundo a teoria utilizada, a motivação das pessoas depende de dois fatores: higiênicos e motivacionais. Os fatores higiênicos referem-se "às condições físicas e ambientais de trabalho, o salário, os benefícios sociais, as políticas da empresa, o tipo de supervisão recebida, o clima de relações entre a direção e os empregados, os regulamentos internos", entre outros. Os fatores motivadores referem-se ao conteúdo do cargo, às tarefas e aos deveres relacionados com o cargo em si, produzindo efeitos duradouros de satisfação e aumento de produtividade em níveis de excelência ${ }^{(6)}$.

Enfocando mais especificamente a administração, a liderança e suas relações com a motivação, é oportuno alertarmos para o perigo do uso da motivação enquanto instrumento para a administração, pois no "contexto administrativo e teórico organizacional, a motivação foi convertida em um instrumento de invasão, manipulação e controle", através do qual os dirigentes podem provocar determinados tipos de comportamento em seus subordinados, pois não é considerado o aspecto individual e intrínseco da motivação, que é usada como substituta do poder e da coação, antes considerados predominantes na tentativa de influenciar os empregados $^{(7)}$.

Nesse contexto, não são possíveis generalizações a respeito da motivação, tornando-se importante considerar a peculiaridade humana, pois os indivíduos possuem desejos e necessidades diferentes e, independentemente da facilidade de compreensão ou da conveniência administrativa, não existe estratégia específica para todos terem produtividade satisfatória ${ }^{(1)}$.

A esse respeito, atitudes profissionais como "apatia, indiferença, descompromisso, irresponsabilidade, relação desumanizada com a clientela, falta de motivação, insatisfação e falta de criatividade" são consideradas decorrentes de dificuldades no desenvolvimento do trabalho da enfermagem, devendo ser ressaltada a necessidade do "desenvolvimento de sensibilidade no que tange a um gerenciamento mais reflexivo, crítico, flexível, humano, que dê oportunidade para maior participação" dos elementos da equipe e dos clientes ${ }^{(8)}$.

Ainda nessa perspectiva, como conseqüência do contexto de trabalho determinado pelas instituições hospitalares, quando não são priorizados os aspectos motivacionais, além do restrito conhecimento do enfermeiro sobre essa temática, "a motivação passa a ser tratada de maneira superficial,... negando-se aspectos intrínsecos que conduzem as pessoas no desempenho profissional"(9).

A existência do pressuposto de que podemos motivar as pessoas, evidencia a necessidade de resgatar a diferenciação entre satisfação e motivação, pois a motivação surge das necessidades humanas e satisfação é considerada 0 atendimento de uma necessidade ou sua eliminação, portanto, considerados opostos e não sinônimos ${ }^{(4)}$.

Ainda devemos destacar que considerar os fatores de satisfação como motivadores levou ao falso pressuposto de que uma pessoa tem o poder de motivar a outra, pois os motivadores estão presentes no meio ambiente ${ }^{(4)}$.

Vale ressaltar que a motivação origina-se das necessidades e não dos fatores de satisfação exógenos, encontrados no ambiente, ou dos fatores de satisfação endógenos, intrínsecos ao indivíduo. 
Portanto, aos "administradores resta apenas gerenciar os fatores de satisfação e contra-satisfação exógenos", sendo o primeiro, aquele que eleva o nível de satisfação e o segundo, aquele que aumenta a tensão da necessidade pela privação do seu atendimento ${ }^{(10)}$.

Assim, considerar a motivação como resultado de fatores que residem fora do indivíduo agrada a muitos supervisores e gerentes, pois podem atribuir as causas da falta de motivação daqueles aos quais supervisionam, ou dizem administrar, somente às organizações. Portanto, deve ser examinado cuidadosamente no que consiste o fenômeno da liderança diante do despreparo dos administradores de recursos humanos, em decorrência dos efeitos danosos provocados por um vínculo de chefia inadequado que, associado à filosofia organizacional, impede a criação de um ambiente motivacional $^{(11)}$

Diante dessas considerações, emergiram as seguintes indagações: Como motivar os elementos da equipe de enfermagem? Quais as preferências motivacionais dos elementos da equipe de enfermagem? Na tentativa de buscarmos novos conhecimentos para responder a estas indagações, bem como buscar elementos que norteiem a compreensão a respeito do comportamento das pessoas no trabalho, propusemo-nos a realizar este estudo sobre os aspectos motivacionais da equipe de enfermagem, com os seguintes objetivos: 1) conhecer a opinião do pessoal de enfermagem sobre a motivação no trabalho; 2) identificar aspectos que contribuem para a motivação e para a desmotivação no trabalho.

\section{TRAJETÓRIA METODOLÓGICA}

Trata-se de um estudo descritivo, realizado segundo a metodologia quanti-qualitativa, onde buscamos conhecer aspectos motivacionais do trabalho através das falas do pessoal de enfermagem, sendo a entrevista semi-estruturada e gravada, escolhida como técnica para coleta de dados.

Para a realização das entrevistas, elaboramos um roteiro constituído de duas partes: a primeira voltada à caracterização dos sujeitos, e a segunda composta de questões abertas, norteadoras do estudo. São elas: "No seu dia-a-dia quais situações contribuem para você sentir-se motivado?"; "Quais situações contribuem para você sentir-se desmotivado?"; "Quais medidas poderiam ser tomadas para elevar a motivação entre os elementos da equipe de enfermagem?".

Participaram desta pesquisa, 18 profissionais da equipe de enfermagem, sendo 6 enfermeiros e 12 profissionais de nível médio (técnicos e auxiliares de enfermagem), com disposição positiva para participar do estudo, selecionados a partir de sorteio, sendo portanto amostra aleatória. Definimos o número de sujeitos participantes do estudo, a partir do momento que houve convergência nos relatos.

Anteriormente à coleta de dados, solicitamos autorização da Comissão de Normas Éticas do hospital em estudo, para realizarmos este procedimento, mediante a apreciação do projeto de pesquisa. Cada participante assinou termo de consentimento, após a apresentação dos objetivos do estudo, garantia do caráter confidencial e voluntário da participação, bem como o compromisso de lhes comunicarmos os resultados do estudo.

Transcrevemos as entrevistas na íntegra, respeitando a terminologia utilizada pelos entrevistados; posteriormente, submetemos este material à técnica de análise de conteúdo ${ }^{(12)}$.

A partir da transcrição e análise das entrevistas, realizamos o agrupamento das unidades de registro, obtendo, assim, o conjunto de 10 categorias no total, as quais definimos a partir de alguns fatores motivacionais e higiênicos de Herzberg, em decorrência da nãoidentificação de todos os fatores, na fala dos entrevistados. As quatro primeiras categorias, baseadas nos fatores motivacionais, são: trabalho em si, resultado do trabalho, desenvolvimento pessoal/ profissional e reconhecimento pelo trabalho. As demais, relacionamento interpessoal, organização do trabalho, percepções e expectativas em relação à chefia, salário, condições de trabalho e desempenho profissional, estão baseadas nos fatores higiênicos.

\section{APRESENTAÇÃO E ANÁLISE DOS RESULTADOS}

Caracterização dos sujeitos participantes do estudo

Quanto à caracterização dos sujeitos participantes do estudo, $72,2 \%$ são do sexo feminino; $50 \%$ tem idade entre 26 e 35 anos; $50 \%$ deles são casados; $38,8 \%$ possuem entre um (1) e cinco (5) anos de tempo de serviço na unidade e $44,4 \%$ referem renda familiar mensal entre cinco (5) e dez (10) salários-mínimos.

Análise do conteúdo das entrevistas

A análise do conteúdo das entrevistas em relação às questões norteadoras mostra-nos a distribuição das unidades de registro, dentre as dez categorias distintas, de acordo com 0 agrupamento dos temas em fatores motivacionais e higiênicos e suas respectivas categorias. 
Tabela 1 - Distribuição numérica e percentual das unidades de registro identificadas no discurso dos sujeitos em estudo, segundo os temas e respectivas categorias. Ribeirão Preto, 1999

\begin{tabular}{|c|c|c|}
\hline TEHASICategorias & $\mathbf{H}^{\circ}$ & $\%$ \\
\hline \multicolumn{3}{|l|}{ FATORESMOTIWACIONAIS } \\
\hline Resultado do trabalho & 20 & 10,8 \\
\hline Trabalho em si & 18 & 9,7 \\
\hline Reconhecimento pelo trabalho & 15 & 8,1 \\
\hline Desenvolvimento pessoaliprofissional & 10 & 5,4 \\
\hline SUBTOTAL & 63 & 34,0 \\
\hline \multicolumn{3}{|l|}{ FATORESHIGIENNICOS } \\
\hline Relacionamento interpessoal & 44 & 23,8 \\
\hline Organizaçẫo do trabalho & 35 & 18,9 \\
\hline Salário & 23 & 12,4 \\
\hline Desempenho profissional & 11 & 5,9 \\
\hline Percepçôes e expectativas em relaçẫo à chefia & 6 & 3,2 \\
\hline Condiçốes de Trabalho & 3 & 1,6 \\
\hline SUBTOTAL & 122 & 65,8 \\
\hline TOTAL & 185 & 100,0 \\
\hline
\end{tabular}

Como podemos observar, houve maior referência aos fatores higiênicos, com 122 unidades de registro, em relação aos fatores motivacionais, que somaram apenas 63 unidades. Acreditamos que esta preocupação com os aspectos extrínsecos está relacionada à negligência de algumas organizações brasileiras em relação às condições ambientais, pois a atual situação de trabalho tem desagradado a muitos profissionais ${ }^{(1)}$.

A seguir apresentaremos os resultados e a análise dos mesmos, com relação às questões norteadoras do estudo, de acordo com a seqüência do roteiro.

A Tabela 2 permite verificar que, entre as situações consideradas motivadoras, as unidades de registro relacionadas à categoria "Trabalho em si", que apresentou 16 referências, destacase das demais, seguida das categorias "Relacionamento interpessoal", com 14 referências; "Resultado do trabalho", com 10; "Salário", com 7; "Organização do trabalho", com 6; "Reconhecimento pelo trabalho", com 3; "Desenvolvimento pessoal/profissional" e "Desempenho profissional" com 2 citações, respectivamente, e "Percepções e expectativas em relação à chefia" com uma citação.

Tabela 2 - Distribuição numérica e percentual calculada com base no total $(n=185)$ de unidades de registro, identificadas no discurso dos sujeitos em estudo, relacionadas às situações motivadoras. Ribeirão Preto, 1999

\begin{tabular}{lcc}
\hline \multicolumn{1}{c}{ TEHASICategorias } & N $^{\circ}$ & $\%$ \\
\hline FATORESMOTI'uACIONAIS & & \\
Trabalho em si & 16 & 8,6 \\
Resultado do trabalho & 10 & 5,4 \\
Reconhecimento pelo trabalho & 3 & 1,6 \\
Desenvolvimento profissionalipessoal & 2 & 1,1 \\
SUBTOTAL & 31 & 16,7 \\
FATORESHIGIÊNICOS & & \\
Relacionamento interpessoal & 14 & 7,6 \\
Salário & 7 & 3,8 \\
Organizaç ấo do trabalho & 6 & 3,2 \\
Desempenho profissional & 2 & 1,1 \\
Percepçốes e expectativas em relaçẫo à chefia & 1 & 0,5 \\
SUBTOTAL & 30 & 16,2 \\
TOTAL & 61 & 32,9 \\
\hline
\end{tabular}

Assim, ao somarmos as citações das categorias relacionadas aos fatores motivacionais (31) e as categorias referentes aos fatores higiênicos (30), observamos a predominância de fatores motivacionais. Podemos considerar, portanto, a equivalência de valorização tanto dos fatores motivacionais quanto dos higiênicos na verbalização dos entrevistados, em relação às situações motivadoras.

Diante destes valores, parece oportuno resgatar a importância da diferenciação encontrada entre os profissionais regidos por aspectos extrínsecos daqueles realmente motivados pelo trabalho, pois os fatores que estão fora das pessoas, os condicionantes ou reforçadores de comportamentos, como salário, relacionamento interpessoal, políticas organizacionais e condições ambientais de trabalho não motivam, apenas fazem com que as pessoas se movimentem e caso estes deixem de existir, o comportamento desejado também desaparece ${ }^{(11)}$.

Quanto às categorias relacionadas a situações desmotivadoras, constata-se (Tabela 3) que a "Organização do trabalho" surge como a mais citada, com 14 indicações, seguida do "Relacionamento interpessoal", com 12; "Resultado do trabalho", com 10; "Salário", com 9; "Reconhecimento pelo trabalho", com 7; "Desempenho profissional", com 4, as categorias "Desenvolvimento pessoal/profissional", "Percepções e expectativas em relação à chefia" e "Condições de trabalho" com 2 cada uma.

Tabela 3 - Distribuição numérica e percentual calculada com base no total $(n=185)$ de unidades de registro, identificadas no discurso dos sujeitos em estudo, relacionadas às situações desmotivadoras. Ribeirão Preto, 1999

\begin{tabular}{|c|c|c|}
\hline TEHASICategorias & $\mathrm{H}^{\mathrm{O}}$ & $\%$ \\
\hline 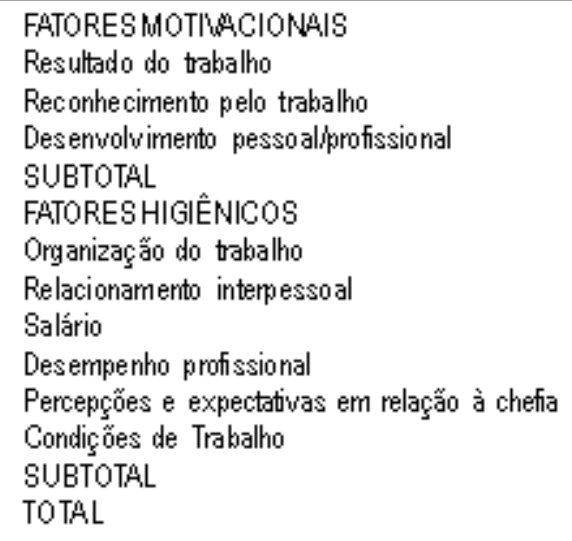 & $\begin{array}{c}14 \\
12 \\
9 \\
4 \\
2 \\
2 \\
43 \\
62\end{array}$ & $\begin{array}{r}5,4 \\
3,8 \\
1,1 \\
10,3 \\
7,6 \\
6,5 \\
4,8 \\
2,1 \\
1,1 \\
1,1 \\
23,2 \\
33,5\end{array}$ \\
\hline $\begin{array}{l}\text { Convém destacar que "Trabalho em } \\
\text { excluída das situações consideradas desmoti } \\
\text { que teve maior número de citações, quando ab } \\
\text { motivadoras no trabalho. Isto confirma que } 0 \\
\text { referem-se ao conteúdo do cargo, às tar } \\
\text { relacionados com o cargo em si, produzindo } \\
\text { satisfação e aumento de produtividade em ní }\end{array}$ & a únice & $\begin{array}{l}\text { ategoria } \\
\text { tegoria } \\
\text { tuações } \\
\text { vadores } \\
\text { leveres } \\
\text { uros de }\end{array}$ \\
\hline
\end{tabular}


A distribuição das categorias referentes às sugestões apresentadas pelos profissionais, para elevar a motivação no trabalho, demonstra, a partir da Tabela 4, que o "Relacionamento interpessoal" apresenta-se com o maior número de citações (18), seguido de "Organização do trabalho", com 15; de "Salário", com 7; "Desenvolvimento pessoal/profissional", com 6; "Reconhecimento pelo trabalho" e "Desempenho profissional", com 5 cada uma, e "Percepções e expectativas em relação à chefia", com 3; "Trabalho em si", com 2 e "Condições de trabalho" com 1 citação.

Vale ressaltar que a categoria "Resultado do trabalho" não foi citada nas sugestões apresentadas pelos profissionais, apesar da representativa aparição em relação às situações motivadoras e desmotivadoras.

Tabela 4 - Distribuição numérica e percentual calculada com base no total $(n=185)$ de unidades de registro, identificadas nos discursos dos sujeitos em estudo, relacionadas às sugestões apresentadas. Ribeirão Preto, 1999

\begin{tabular}{|c|c|c|}
\hline TEMASICategorias & $\mathbf{N}^{\circ}$ & $\%$ \\
\hline \multicolumn{3}{|l|}{ FATORESMOTKACIONAIS } \\
\hline $\begin{array}{l}\text { Desenvolvimento pessoaliprofissional } \\
\text { Reconhecimento pelo trabalho }\end{array}$ & $\begin{array}{l}6 \\
5\end{array}$ & $\begin{array}{l}3,2 \\
27\end{array}$ \\
\hline Trabalho em si & 2 & 1,1 \\
\hline $\begin{array}{l}\text { SUBTOTAL } \\
\text { FATORESHIGIÊNICOS }\end{array}$ & 13 & 7,0 \\
\hline Relacionamento interpessoal & 18 & 9,7 \\
\hline Organizaç ẫo do trabaltho & 15 & 8,1 \\
\hline Salário & 7 & 3,8 \\
\hline Desempenho profissional & 5 & 2,7 \\
\hline Percepçốes e expectativas em relaçấo à chefia & 3 & 1,6 \\
\hline Condiçônes de Trabalho & 1 & 0,5 \\
\hline SUBTOTAL & 49 & 26,4 \\
\hline TOTAL & 62 & 33,4 \\
\hline
\end{tabular}

A análise sobre a questão "Trabalho em si", como principal motivador no trabalho, permite inferir que o cuidado ao paciente pode ser considerado o alicerce da prática de enfermagem, enquanto a "Organização do trabalho", como maior desmotivadora, alerta-nos para a importância da "saúde" das organizações. Enfim, a predominância de sugestões acerca do "Relacionamento interpessoal" e "Organização do trabalho" volta o enfoque para o indivíduo, agora como profissional em suas relações dentro de um contexto organizacional, com suas características peculiares, que não impede sua transformação e reestruturação, pois a sua finalidade é garantir que ele alcance tanto os objetivos individuais quanto os organizacionais ${ }^{(13)}$.

\section{CONSIDERAÇÕES FINAIS}

A realização deste trabalho permite concluir que o estudo da motivação, em decorrência da sua complexidade e dificuldade, parece não ser esgotável, necessitando, assim, de maior aprofundamento e atenção das organizações e instituições formadoras. Além disso, há a dificuldade da abordagem do tema "motivação" entre os elementos da equipe de enfermagem, dentro do atual contexto dos serviços públicos de saúde no Brasil.

A política atual de racionalização de recursos humanos, materiais e financeiros é responsável pelo achatamento salarial, devido a inexistência de reajustes, levando a maioria desses profissionais à dupla jornada de trabalho; pela não-contratação de pessoal, mesmo para reposição de demissões ou aposentadorias, resultando em sobrecarga de trabalho para o pessoal e ainda pelas restrições quanto à disponibilidade de recursos materiais que exige a constante adaptação do profissional para a execução das tarefas diárias, significando muitas vezes, maior tempo despendido, o que contribui para a existência de um ambiente insatisfatório.

Ao considerarmos a distribuição das unidades de registro no discurso dos profissionais, constatamos que 122 referências são relacionadas aos fatores higiênicos e 63 aos motivacionais. Isto confirma que algumas organizações brasileiras negligenciam os aspectos extrínsecos do trabalho, quando deveria ocorrer o contrário, pois como são raras as ofertas de fatores motivadores, maior deveria ser 0 oferecimento de fatores higiênicos, para que o trabalho possa ser tolerável ${ }^{(1)}$.

Em relação às situações referidas como motivadoras, a categoria "Trabalho em si" surge como mais citada, também confirmando a assertiva de que os fatores relacionados ao próprio trabalho, às tarefas e deveres relacionados ao cargo em si, ou seja, o cuidado ao paciente, recompensam o indivíduo, pelo fato de nele encontrar 0 atendimento das próprias aspirações ${ }^{(1)}$.

A segunda categoria mais referida, em relação às situações motivadoras, é "Relacionamento interpessoal", e por se tratar de fator higiênico e, portanto, extrínseco, podemos considerar que o bom relacionamento no ambiente de trabalho precisa ser garantido para que seja reduzida ao máximo a insatisfação no contexto de trabalho, confirmando o que dissemos anteriormente.

Quanto às situações desmotivadoras, a "Organização do trabalho" predomina, confirmando as implicações negativas em relação à motivação, provocadas pelos aspectos relacionados à organização do trabalho, pois o modo como somos tratados nas organizações que trabalhamos ou a que pertencemos, as normas, os valores vigentes, os tipos de autoridade e poder exercidos afetam as ações e os motivos que nos levam a agir ${ }^{(2)}$. A seguir vem a categoria "Relacionamento interpessoal", a segunda mais citada como desmotivadora

Vale ressaltar que entre as 10 categorias emergentes do discurso dos profissionais, apenas "Trabalho em si" não foi referida como desmotivadora. 
As categorias mais citadas, como sugestões para elevar a motivação são "Relacionamento interpessoal" e "Organização do trabalho", ou seja, aspectos do trabalho que podem ser transformados através de investimentos na área de recursos humanos e de mudanças na política organizacional. 0 desejo dos profissionais quanto às mudanças em relação a esses aspectos do trabalho merece atenção, pois, apesar de extrínsecos, a garantia desses aspectos proporciona oportunidade para que a motivação do profissional seja refletida no alcance dos objetivos da organização. Vale dizer que as várias organizações dependem dos diferentes tipos de autoridade $\mathrm{e}$ de poder, o que limita o envolvimento dos seus membros ${ }^{(2)}$.

\section{REFERÊNCIAS BIBLIOGRÁFICAS}

1. Bergamini CW. Revisão crítica dos conceitos tradicionais de motivação e levantamento de um perfil motivacional brasileiro.[dissertação]. São Paulo (SP): Faculdade de Economia e Administração/USP; 1983.

2. Schein EH. Psicologia organizacional. $3^{\mathrm{a}}$ ed. Rio de Janeiro (RJ): Prentice-Hall; 1982.

3. Ferreira $A B H$. Novo dicionário da língua portuguesa. $2^{a}$ ed. Rio de Janeiro (RJ): Nova Fronteira; 1986.

4. Archer ER. O mito da motivação. In: Bergamini CW, Coda R, organizadores. Psicodinâmica da vida organizacional: motivação $e$ liderança. São Paulo (SP): Pioneira 1990. p. 3-24.

5. Herzberg F. The motivation to work. New York: John Wiley; 1959.

6. Chiavenato I. Recursos humanos - edição compacta. $4^{a}$ ed. São Paulo (SP): Atlas; 1990.
Tendo em vista o tema que abordamos neste estudo, ou seja, a motivação enquanto aspecto intrínseco e individual, mas influenciada por fatores externos, não acreditamos que caibam aqui generalizações. A análise percentual dos dados permite apenas considerar perspectivas comuns no decorrer das experiências vividas, numa determinada cultura, dentro de uma organização.

Este estudo, portanto, deve ser considerado uma aproximação ao tema proposto, em especial no trabalho de enfermagem, pois seu intuito é contribuir para a maior compreensão do fenômeno motivacional.

7. Sievers B. Além do sucedâneo da motivação. In: Bergamini CW, Coda R, organizadores. Psicodinâmica da vida organizacional: motivação e liderança. São Paulo (SP): Pioneira; 1990. p. 105-123. 8. Fávero N. O gerenciamento do enfermeiro na assistência ao paciente hospitalizado. [dissertação]. Ribeirão Preto (SP): Escola de Enfermagem/USP; 1996.

9. Reis JN. A motivação humana no trabalho administrativo do enfermeiro na realidade hospitalar: aspectos teóricos.[dissertação]. Ribeirão Preto (SP): Escola de Enfermagem/USP; 1993.

10. Cunha KC. $O$ contexto e o processo motivacional vivenciado por enfermeiras. [dissertação]. São Paulo (SP): Escola de Enfermagem/ USP; 1994.

11. Bergamini CW. Motivação. São Paulo (SP): Atlas; 1993.

12. Bardin L. Análise de conteúdo. Lisboa: Edições 70; 1991.

13. Alves-Pereira MC. Aspectos motivacionais da equipe de enfermagem no trabalho. [dissertação]. Ribeirão Preto (SP): Escola de Enfermagem/USP; 1999. 